\title{
Application of expert evaluation method for realization of tasks in construction industry
}

\author{
Anatoly Efimenko, ${ }^{1, *}$, Ivan Zlobin ${ }^{1}$, Andrey Avilov ${ }^{1}$ and Alexander Markov ${ }^{1}$ \\ ${ }^{1}$ Moscow State University of Civil Engineering, 26, Yaroslavskoe Shosse, Moscow, Russia
}

\begin{abstract}
In this article expert evaluation method is presented in the scope of production management in construction tasks realization detailing the nature, features and methods of implementation. Theoretical concepts are illustrated with examples and comments of the results, which contributes to a better understanding and practical application of the expert evaluation method. We recommend following method to form the expert group that will ensure the competence of their future judgments: the organizers of the expert analysis develop, on their own judgment, a list of ten people, who in turn will name ten more people, who are they believe would be necessary to include in the number of experts. From 110 candidates obtained that way, ones who are mentioned most commonly in the lists are chosen. Normally, this number would not exceed 20-30 people. The material in the article allows us to conclude that the possibilities of the method are quite broad, it can be used in solving various problems in the field of the construction industry.
\end{abstract}

\section{Introduction}

Expert evaluation method is widely applied in people's practical activities. This can be explained by the fact that the method is based on the postulate: the sum of knowledge of a certain group of people, is always more than knowledge of each one of them individually. Practice shows, that realization of production tasks is usually more successful if it relies on collective experience, collective mind of people [1-3].

Quite often relationship between the qualitative content of the process (phenomenon) and necessary activities or assessments is very complex, relevant patterns are not always known, and if known, usually only in qualitative terms. Therefore, it is not yet possible to formalize the process of implementation of measures or obtaining evaluations in such conditions. This leads to the need for application of expert evaluation method $[4,5]$.

In this article expert evaluation method is presented in the scope of production management in construction tasks realization detailing the nature, features and methods of implementation $[6,7,8]$. Theoretical concepts are illustrated with examples and comments of the results, which contributes to a better understanding and practical application of the expert evaluation method.

\footnotetext{
*Corresponding author: EfimenkoAZ@mgsu.ru
} 


\section{Methods}

In its content, expert evaluation method in the general case includes following: to solve the tasks experts propose activities with individual assessments of their effectiveness (or assess realized activities), which are based on the experience and intuition of experts; and which is the first (heuristic) part of the method; then individual assessments are processed using methods of mathematical statistics, resulting in generalized assessment, more convenient for practical use, which is the second (mathematical) part of the method $[9,10]$.

During selection of experts they are required to have necessary qualifications, experience and knowledge of the research subject, practical experience of resolving similar tasks or theoretical backing, appropriate educational qualifications and lack of personal stake in the nature of decisions.

We recommend following method to form the expert group that will ensure the competence of their future judgments: the organizers of the expert analysis develop, on their own judgment, a list of ten people, who in turn will name ten more people, who are they believe would be necessary to include in the number of experts. From 110 candidates obtained that way, ones who are mentioned most commonly in the lists are chosen. Normally, this number would not exceed 20-30 people.

Then in the second round, those 20-30 expert candidates are invited again to list 10 people, they would recommend into the expert group, and again, most frequently listed names are selected. Of these people, an expert group is formed, the necessary number of which is determined by the existing empirical formulas.

The required number of experts $\mathrm{N}$ is determined on the basis of the hypothesis that the concordance coefficient is equal to 0.5 or more than 0.5 , i.e. $\mathrm{W}>0.5$ :

$$
N=\left(K * P_{g}\right) /\left(P_{0 W}+W\right)
$$

$K$ - number of assessed factors (suggestions, recommendations);

$P_{g}$ - probability belief; $P_{g}=0,9$;

$P_{O W}$ - tolerable error; $P_{O W}=0,2$;

$W$ - concordance coefficient.

For example, with 19 evaluated factors, necessary number of experts will be:

$$
N=(19 * 0,9) /(0,2+0,5)=24,429 \approx 25
$$

Optimum solution is obtained with the help of expert evaluation method is performed in the following sequence:

Problem statement. Problem statement should reflect all characteristics of the researched process participants, outlined mandatory restrictions, possible local and systemic criteria and a type of the result.

Composition and determination of the required number of experts.

Implementation of the expert evaluation method or more of its varieties. A combination of brainstorming technique and referred valuation method. Using brainstorming technique list of proposals (recommendations) for realization of tasks is developed. Using referred valuation method, the importance of the proposals is assessed on arbitrary scale, convenient to work with. The ten-point scale is mainly used: if the proposal, according to the expert, is of the highest importance, then a score of 10 is attributed to it; if the proposal has no significance, then zero is assigned to it; all other assessments get scores in integers from 0 to 10; evaluations of different proposals by one expert may be the same if, in his opinion, they have the same significance.

Obtaining generalized estimates. Generalized (integral) evaluations result from processing of individual assessments using methods of mathematical statistics. 


\section{Results and Discussion}

In order to find ways to improve the quality of ceramic floor tiles $[11,12]$, a group of 9 experts was selected. Using brainstorming technique they identified recommendations for improving the quality of this product and determined the significance of each proposal on a ten-point system by the referred valuation method. Expert poll results are summarized in Table 1.

Table 1. Expert poll results are summarized.

\begin{tabular}{|l|c|c|c|c|c|c|c|c|c|}
\hline \multicolumn{1}{|c|}{ Suggestions } & \multicolumn{7}{|c|}{ Expert evaluations } \\
\cline { 2 - 11 } & 1 & 2 & 3 & 4 & 5 & 6 & 7 & 8 & 9 \\
\hline 1. Use of natural clay processing methods & 5 & 2 & 7 & 7 & 1 & 8 & 6 & 2 & 4 \\
\hline 2. Introduction of combined flux agent & 5 & 5 & 6 & 7 & 4 & 6 & 6 & 5 & 10 \\
\hline $\begin{array}{l}\text { 3. The introduction of new, better compositions } \\
\text { of glazing }\end{array}$ & 6 & 5 & 6 & 5 & 6 & 7 & 7 & 6 & 8 \\
\hline $\begin{array}{l}\text { 4. Application of slip method for preparation of } \\
\text { mass }\end{array}$ & 8 & 6 & 7 & 4 & 6 & 5 & 6 & 7 & 5 \\
\hline $\begin{array}{l}\text { 5. The use of tower spray dryers for dehydration } \\
\text { of the slip }\end{array}$ & 9 & 8 & 10 & 9 & 6 & 8 & 6 & 5 & 8 \\
\hline $\begin{array}{l}\text { 6. Strengthening control over the quality of raw } \\
\text { materials and finished products }\end{array}$ & 10 & 8 & 9 & 8 & 7 & 6 & 7 & 9 & 10 \\
\hline $\begin{array}{l}\text { 7. Compliance with optimum technological } \\
\text { parameters }\end{array}$ & 8 & 10 & 10 & 10 & 10 & 8 & 9 & 10 & 10 \\
\hline 8. Advanced training of workers & 6 & 5 & 6 & 7 & 5 & 8 & 9 & 8 & 10 \\
\hline 9. Advanced training of engineers & 7 & 5 & 6 & 6 & 5 & 8 & 9 & 8 & 10 \\
\hline 10. Improving financial incentives for staff & 9 & 5 & 6 & 5 & 4 & 8 & 7 & 10 & 10 \\
\hline
\end{tabular}

Results of The Calculations

Average valuations

$\begin{array}{llllllllll}4.667 & 6.000 & 6.222 & 6.000 & 7.667 & 8.222 & 9.444 & 7.111 & 7.111 & 7.111\end{array}$

Dispersions

$\begin{array}{llllllllll}6.500 & 3.000 & 0.944 & 1.500 & 2.750 & 1.944 & 0.778 & 3.111 & 3.111 & 5.111\end{array}$

Standard deviation

$\begin{array}{llllllllll}2.550 & 1.732 & 0.972 & 1.225 & 1.658 & 1.394 & 0.882 & 1.764 & 1.764 & 2.261\end{array}$

Coefficients of variation

$\begin{array}{llllllllll}0.546 & 0.289 & 0.156 & 0.204 & 0.216 & 0.170 & 0.093 & 0.248 & 0.248 & 0.318\end{array}$

Ranks

$\begin{array}{lllllllll}9.500 & 10.00 & 4.500 & 5.000 & 10.00 & 3.500 & 8.500 & 10.00 & 10.00\end{array}$

$\begin{array}{lllllllll}9.500 & 7.000 & 8.000 & 5.000 & 8.500 & 8.500 & 8.500 & 8.500 & 3.500\end{array}$

$\begin{array}{lllllllll}7.500 & 7.000 & 8.000 & 8.500 & 4.000 & 7.000 & 5.000 & 7.000 & 7.500\end{array}$

$\begin{array}{lllllllll}4.500 & 4.000 & 4.500 & 10.00 & 4.000 & 10.00 & 8.500 & 6.000 & 9.000\end{array}$

$\begin{array}{lllllllll}2.500 & 2.500 & 1.500 & 2.000 & 4.000 & 3.500 & 8.500 & 8.500 & 7.500\end{array}$

$\begin{array}{lllllllll}1.000 & 2.500 & 3.000 & 3.000 & 2.000 & 8.500 & 5.000 & 3.000 & 3.500\end{array}$

$\begin{array}{lllllllll}4.500 & 1.000 & 1.500 & 1.000 & 1.000 & 3.500 & 2.000 & 1.500 & 3.500\end{array}$

$\begin{array}{lllllllll}7.500 & 7.000 & 8.000 & 5.000 & 6.500 & 3.500 & 2.000 & 4.500 & 3.500\end{array}$

$\begin{array}{lllllllll}6.000 & 7.000 & 8.000 & 7.000 & 6.500 & 3.500 & 2.000 & 4.500 & 3.500\end{array}$

$\begin{array}{lllllllll}2.500 & 7.000 & 8.000 & 8.500 & 8.500 & 3.500 & 5.000 & 1.500 & 3.500\end{array}$

Sum of ranks

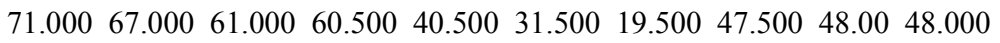

Concordance coefficient

\subsection{2}

Pair rank correlation coefficient

$\begin{array}{rrrrrrrrl}1.000 & 0.719 & 0.501 & 0.181 & 0.584 & -0.028 & 0.124 & 0.598 & 0.229 \\ 0.719 & 1.000 & 0.742 & 0.514 & 0.892 & -0.176 & 0.134 & 0.442 & 0.220 \\ 0.501 & 0.742 & 1.000 & 0.668 & 0.610 & 0.033 & -0.210 & 0.020 & -0,265\end{array}$


$\begin{array}{lllllllll}0.181 & 0.514 & 0.668 & 1.000 & 0.367 & 0.345 & 0.137 & 0.047 & 0.271\end{array}$

$\begin{array}{lllllllll}0.584 & 0.892 & 0.610 & 0.367 & 1.000 & 0.244 & 0.304 & 0.430 & 0.126\end{array}$

$\begin{array}{lllllllll}-0.028 & -0.176 & 0.033 & 0.345 & -0.244 & 1.000 & 0.439 & 0.152 & 0.151\end{array}$

$\begin{array}{lllllllll}0.124 & 0.134 & -0.210 & 0.137 & 0.304 & 0.439 & 1.000 & 0.732 & 0.668\end{array}$

$\begin{array}{lllllllll}0.598 & 0.442 & 0.020 & 0.047 & 0.430 & 0.152 & 0.732 & 1.000 & 0.692\end{array}$

$\begin{array}{lllllllll}0.229 & 0.220 & -0.265 & 0.271 & 0.126 & 0.151 & 0.668 & 0.692 & 1.000\end{array}$

Concordance coefficient

$\begin{array}{lllllllll}0.363 & 0.436 & 0.262 & 0.316 & 0.384 & 0.084 & 0.291 & 0.389 & 0.262\end{array}$

Based on the obtained results we can conclude:

- The most significant were suggestions 7 (compliance with the optimal technological parameters) and 6 (strengthening control over the quality of raw materials and finished products), and the least significant - proposal 1 (the use of natural methods of processing of clay raw materials).

- Obtained coefficients of variation show that the consistency of experts' opinions on the proposals of 2-9 is achieved, and on the proposals 1 (the use of natural methods of processing clay raw materials) and 10 (improvement of financial incentives for workers) consistency of the experts valuations is doubtful $(>0.3)$.

- Concordance coefficient, which characterizes consistency of expert opinions on all proposals, is $\mathrm{W}=0.391$, therefore, the consistency was generally insufficient, since $\mathrm{W}$ $<0.5$.

- Values of the pair rank correlation coefficients allow us to draw following conclusions: completely insufficient consistency between experts 1 and 6,2 and 6,3 and 7, 3 and 9, 5 and 6 , since the values of the coefficients of pair rank correlation are negative.

- All concordance coefficients of each expert with all other experts have values less than 0,5 indicating a lack of consistency among the experts.

With the aim to find ways to improve the quality of products from aerated concrete [13], a group of 9 experts was selected. Brainstorming technique identified recommendations to improve the quality of these products and referred valuation method determined the significance of each proposal on a ten-point system. Results of the expert survey are summarized in table 2. Calculation results in the second case, are not given in the article.

Table 2. Results of the expert survey.

\begin{tabular}{|l|c|c|c|c|c|c|c|c|c|}
\hline \multicolumn{1}{|c|}{ Suggestions } & \multicolumn{7}{|c|}{ Expert evaluations } \\
\cline { 2 - 10 } & 1 & 2 & 3 & 4 & 5 & 6 & 7 & 8 & 9 \\
\hline $\begin{array}{l}\text { 1. Additional grinding of cement and } \\
\text { aluminum powder for their activation }\end{array}$ & 3 & 4 & 3 & 5 & 7 & 6 & 5 & 5 & 8 \\
\hline $\begin{array}{l}\text { 2. Introducing finely dispersed natural or } \\
\text { artificial glass to increase strength }\end{array}$ & 2 & 3 & 2 & 6 & 8 & 5 & 6 & 4 & 5 \\
\hline $\begin{array}{l}\text { 3. Dispersed reinforcement with a fine fiber } \\
\text { additive }\end{array}$ & 5 & 5 & 2 & 6 & 3 & 2 & 2 & 3 & 6 \\
\hline $\begin{array}{l}\text { 4. Implementation of packaged vibration } \\
\text { technology }\end{array}$ & 5 & 6 & 5 & 7 & 5 & 6 & 6 & 8 & 10 \\
\hline $\begin{array}{l}\text { 5. Introduction of plasticizing agents to } \\
\text { reduce water content in the mixture }\end{array}$ & 3 & 4 & 5 & 7 & 5 & 6 & 5 & 9 & 8 \\
\hline $\begin{array}{l}\text { 6. Improving the homogeneity of the } \\
\text { mixture due to the joint grinding of } \\
\text { components and mixing in vibratory } \\
\text { mixers }\end{array}$ & 5 & 6 & 3 & 7 & 7 & 5 & 6 & 7 & 8 \\
\hline $\begin{array}{l}\text { 7. Pre-autoclaved "maturing" of aerated } \\
\text { concrete massifs }\end{array}$ & 4 & 5 & 5 & 6 & 8 & 4 & 5 & 2 & 5 \\
\hline 8. Advanced training of workers & 5 & 6 & 7 & 7 & 8 & 4 & 7 & 7 & 10 \\
\hline 9. Advanced training of engineers & 5 & 6 & 7 & 7 & 8 & 5 & 7 & 8 & 10 \\
\hline 10. Improving financial incentives for staff & 5 & 5 & 4 & 6 & 8 & 4 & 8 & 10 & 10 \\
\hline
\end{tabular}


Based on the obtained results we can conclude:

- Proposals 9 (advanced training of engineers) and 8 (advanced training of workers) turned out to be the most significant, while proposal 3 (dispersed reinforcement with a fine fiber additive) was least significant.

- Obtained coefficients of variation show that the consistency of experts' opinions on proposals of 4, 6, 8, 9 is achieved, and on 1, 2, 3, 5, 7, 10 consistency of experts is in doubt $(>0.3)$.

Concordance coefficient, which characterizes consistency of expert opinions on all proposals, is $\mathrm{W}=0.412$, therefore, the overall consistency was insufficient, since $\mathrm{W}<0.5$.

Values of the pair rank correlation coefficients allow us to draw following conclusions: completely insufficient consistency between experts 1 and 5,1 and 6,2 and 6, 4 and 5, 5 and 6,6 and 7, 8 and 5, since the values of the coefficients of pair rank correlation are negative. Consistency of each of the experts with all other experts was sufficient only expert 9 , since $\mathrm{W}=0.525>0.5$.

\section{Conclusions}

The material in the article allows us to conclude that the possibilities of the method are quite broad, it can be used in solving various problems in the field of the construction industry. Decisions formed during the examination represent objective opinion of a group of people with necessary qualifications. Even though, there are subjective elements presented in the decision-making process (during problem statement, scale establishment, etc.), in their essence solutions have objective character, supported by alignment of opinions of many qualified professionals.

\section{References}

1. L.V. Kievskiy, I.L. Kievskiy, Int. Journal of Applied Engineering Research 11 (2016)

2. P. Oleynik, N. Cherednichenko, MATEC 196 (2018) S. Sinenko, A. Slavina, Paper presented at the MATEC Web of Conferences 106 (2017) doi:10.1051/matecconf $/ 201710608016$

3. A. Lapidus, T. Bidov, A. Khubaev, MATEC Web of Conferences 117 (2017) doi: 10.1051/matecconf/201711700094

4. A. Lapidus, T. Bidov, A. Khubaev, MATEC Web of Conferences 251 (2017) doi: 10.1051/matecconf/201825105014

5. S.O. Podunavac-Kuzmanović, J.G. Ranogajec, S.Z. Kovačević, Acta Periodica Technologica 46 (2015) DOI: 10.2298/APT1546169P

6. S. Sinenko, A. Ahmetgaliev, A. Slavin, IOP Conference Series: Materials Science and Engineering 365(6), 062039 (2018)

7. J.V. Abellán-Nebot, Quality Engineering (2017) doi: 10.1080/08982112.2017.1385078

8. T. Manfredini, M. Hanuskova, J. of Constr. Engineering and Manag. 47(4) (2012)

9. J. Wille, Sand-Mangel könnte Bauen teurer machen, (2018)

10. R.V. Lesovik, A.N. Nosova, A.V. Savin, E.V. Fomina, World Applied Sciences Journal 29(12), 1600-1604 (2014)

11. M. Fakhratov, R. Erkenov, A. Kulchaev, A. Zavgorodniy, MATEC Web of Conferences 117 (2017) doi: 10.1051/matecconf/201711700043

12. A.P.C. Chan, A.P.L. Chan, Benchmarking, 11(2), 203-221 (2004) 